\title{
Study of association of lateral implantation of placenta with development of preeclampsia and its outcome
}

\author{
Vandana Ambastha, Sreelatha S, Asha Devi, Shruthi Kallesh, Sumaiah, Kavitha LB, \\ Sandeep, Rajeshwari \\ Correspondence: Sreelatha S, Professor, Department of Obstetrics and Gynaecology, ESIC \\ MC PGIMSR, Bangalore- 560010, Karnataka, India; Email - dr.sreelatha2011@gmail.com
}

Distributed under Creative Commons Attribution-Share Alike 4.0 International.

\begin{abstract}
Background: Pre eclampsia (PE) is a life threatening multisystem disorder, unique to pregnancy, complicating approximately $28 \%$ of pregnancies in developed countries and approximately $5-8 \%$ in developing countries. It is the $2^{\text {nd }}$ most important cause of maternal mortality in the world. The search for an ideal predictive test for PE still remains a major challenge for obstetricians. Objectives: To study whether ultrasonologically identified placental laterality can be used as a predictor of pre eclampsia. To assess the incidence of pre eclampsia and other feto-maternal outcome with centrally located placenta and those with laterally located placenta. Methods: This prospective study was conducted on 250 uncomplicated primigravidas with singleton pregnancy attending the antenatal clinic from January 2016 to June 2017. Patients were subjected to ultrasound examination and placental location was determined between 18-24 weeks and again between 32-36 weeks period of gestation. These cases were followed till the delivery. Results: Out of total 250women, 148 had central placenta, in which 8 (5.41\%) developed preeclampsia, while 102 had lateral placenta, in which $40(39.22 \%)$ developed preeclampsia. Thus, in total 48 women developing PE, $40(83.33 \%)$ had lateral placenta whereas, only 8 $(16.67 \%)$ had central placenta. The difference was found to be statistically significant as $p$ value is $<0.001$, sensitivity is $84 \%$ and specificity is $70 \%$. Conclusion: From the above study we concluded that women with laterally located placenta determined by USG have 5 times greater risk of developing PE. So, placental laterality is a simple yet reliable and cost effective predictive screening test for pre-eclampsia.
\end{abstract}

Keywords: Ultrasonography, placental laterality, pre eclampsia, central placenta, intra uterine growth restriction.

Hypertensive disorders are the $2^{\text {nd }}$ most important cause of maternal mortality in world after haemorrhage. Hypertensive disorders complicating pregnancy form one of the deadly triad, along with haemorrhage and sepsis ${ }^{1}$. Hypertension complicates $7-10 \%$ of pregnancies, of which $70 \%$ are caused by gestational hypertension and pre-eclampsia and $30 \%$ caused by chronic hypertension ${ }^{2}$.
Pre-eclampsia is defined as rise of blood pressure $>/=140 / 90 \mathrm{~mm}$ of $\mathrm{Hg}$ recorded on two occasions 6 hours apart with proteinuria $(0.3$ grams or more protein in 24 hour collected urine sample or $1+$ or greater in urine dipstick test) after 20 weeks of gestation in a previously normotensive patient. It affects $5-7 \%$ of first pregnancies and $2-10 \%$ of all pregnancies ${ }^{2}$.

Received: $2^{\text {nd }}$ January 2018. Accepted: $14^{\text {th }}$ April 2018.

Ambastha V, Sreelatha S, Devi A, Kallesh S, Sumaiah, Kavitha LB, Sandeep, Rajeshwari. Study of association of lateral implantation of placenta with development of preeclampsia and its outcome. The New Indian Journal of OBGYN. 2018; 5(1): 33-37. 
Pre eclampsia is a disease of trophoblastic tissues. Quantitative analysis of trophoblast invasion in preeclampsia had shown restricted invasion of trophoblastic cells in pre-eclampsia ${ }^{2}$. Pre-eclampsia occurs only in the presence of placenta ${ }^{3}$. Placenta is the vital link between the mother and the fetus for metabolic exchange, endocrine and other body functions. The blood supply of placenta is not uniformly distributed. As such the site of implantation and resultant location of placenta within the uterus are likely important determinants of placental blood flow and therefore pregnancy success. It has been shown that in humans, both uterine arteries have a significant number of branches and that each supplies corresponding side of uterus ${ }^{4}$. Although anastomoses between the two uterine arteries exist, there is no proof that these are functional. In patients with centrally located placenta both uterine arteries demonstrated similar resistance and the uteroplacental blood flow needs are met by equal distribution from both uterine arteries. However, when placenta is laterally located, in the majority of cases, the uteroplacental blood flow needs are met with primarily by one of the uterine arteries with some contribution from the other uterine artery via collateral circulation. The degree of collateral circulation may not be the same in all subjects and deficient contribution may facilitate the development of pre-eclampsia, intrauterine growth retardation or both. The significance of normal placentation for this cytotrophoblastic invasion is high and the cytotrophoblasts fail to adapt a vascular adhesions phenotype in pre-eclampsia.

There is a significant association between placental location and uterine artery resistance and adverse outcomes such as pre-eclampsia, intra uterine growth restriction (IUGR) or both. Thus, placental location determined by ultrasonography (USG) between 18-24 weeks is a non invasive, cost effective, safe predictor of pre-eclampsia. So, this study was conducted to find out whether the laterality of placenta between 18-24 weeks, can be used as a predictor of pre-eclampsia and other adverse feto-maternal outcomes.

\section{Materials and Method}

A prospective study was conducted on 250 pregnant women who attended Antenatal clinic at ESIC MC \& PGIMSR Hospital, Bangalore over a period of 18 months from January 2016 to June 2017.
Inclusion criteria: Primigravida attending the antenatal clinic, both outpatients and ward admissions, at 18 to 24 weeks of gestation and at 32-36 weeks of gestation without any high risk factors included in the study.

Exclusion criteria: Pregnant women excluded from the study having chronic hypertension or essential hypertension, diabetes mellitus, renal disease, severe anemia, connective tissue disorder, positive lupus anticoagulant anticardiolipin antibodies, $\mathrm{Rh}$ incompatibility, twin pregnancy or positive VDRL test.

A detailed history (history of abruptio placenta, hypertension, pre-eclampsia, intrauterine death, diabetes mellitus) was taken. General physical examination including vital signs (especially blood pressure, weight) was done. Detailed per abdomen examination was done. The location of placenta by ultrasound was done between 18 to 24 weeks and between 32 weeks and 36 weeks. The placenta classified as central when it is equally distributed between the right and left side of the uterus irrespective of anterior, posterior or fundal position. When more than $75 \%$ of the placental mass is to one side of the midline, it is classified as unilateral right or left placenta. The end point of the study was the development of hypertension as per American criteria of obstetrics and gynaecology criteria of delivery. The pregnancy outcome was assessed with respect to incidence of pre eclampsia with lateral location of placenta. Data were analysed by using descriptive statistics and other appropriate statistical methods.

\section{Results}

Majority of the patients (135) were in the study of the age group between 21-25 years (Table 1). Out of 250

Table 1. Distribution according to age group

\begin{tabular}{ccc}
\hline Age group & Frequency & Percent \\
\hline $16-20 y r s$ & 28 & 11.2 \\
$21-25 y r s$ & 135 & 54.0 \\
$26-30 y r s$ & 72 & 28.8 \\
$>30 y r s$ & 15 & 6.0 \\
Total & 250 & 100.0 \\
\hline
\end{tabular}

women, $148(59.2 \%)$ patients had central placenta and $102(40.8 \%)$ patients had unilateral left or right placenta (Table 2). In this study, 54\% of patients having lateral placenta delivered by caesarean section while only $37 \%$ 
of patients having central placenta underwent caesarean section. In our study, total 39 patients develop pre

Table 2. Distribution according to location

\begin{tabular}{lcc}
\hline Location & Frequency & Percent \\
\hline Central & 148 & 59.2 \\
Lateral & 102 & 40.8 \\
Total & 250 & 100.0 \\
\hline
\end{tabular}

eclampsia,, in which $33(84.62 \%)$ had lateral placenta and only $6(15.38 \%)$ patients had central placenta. Twenty five patients developed IUGR, in which 17 (68\%) patients had lateral placenta and only 8 (32\%) patients had central placenta. Total 19 patients developed gestational

Table 3. Distribution according to mode of delivery and location

\begin{tabular}{llll}
\hline $\begin{array}{l}\text { Modes of } \\
\text { delivery }\end{array}$ & Location & \multicolumn{2}{l}{ Total } \\
\cline { 2 - 3 } Central & Lateral & \\
\hline LSCS & $55(37.2 \%)$ & $55(53.9 \%)$ & $110(44.0 \%)$ \\
Vaginal & $93(62.8 \%)$ & $47(46.1 \%)$ & $140(56.0 \%)$ \\
\hline P value $=<0.001$ significant &
\end{tabular}

hypertension in which $12(63 \%)$ had lateral placenta and 9 (37\%) patients had central placenta. In total 250 patients, 9 patients developed PIH +IUGR, in which 7 had lateral

Table 4. Distribution according to outcome and location

\begin{tabular}{llll}
\hline \multirow{2}{*}{ Outcome } & \multicolumn{2}{l}{ Location } & \multirow{2}{*}{ Total } \\
\cline { 2 - 3 } Central & Lateral & \\
\hline NA & $125(84.5 \%)$ & $29(28.7 \%)$ & $154(61.8 \%)$ \\
IUGR & $8(5.4 \%)$ & $17(16.7 \%)$ & $25(10.0 \%)$ \\
GHTN & $7(4.7 \%)$ & $12(11.8 \%)$ & $19(7.6 \%)$ \\
PE & $6(4.1 \%)$ & $33(32.4 \%)$ & $39(15.6 \%)$ \\
PIH+IUGR & $2(1.4 \%)$ & $7(6.9 \%)$ & $9(3.6 \%)$ \\
PPROM & 0 & $2(2.0 \%)$ & $2(0.8 \%)$ \\
PPROM+IUGR & 0 & $2(2.0 \%)$ & $2(0.8 \%)$ \\
Total & $148(100 \%)$ & $102(100 \%)$ & $250(100 \%)$ \\
\hline NA-Normal, & IUGR-Intrauterine & growth restriction, GHTN- \\
Gestational hypertension, PE-Preeclampsia, PIH-Pregnancy induced \\
hypertension, PPROM - Preterm premature rupture of membrane \\
\hline \multicolumn{4}{l}{} \\
\hline
\end{tabular}

Table 5. Distribution according to preeclampsia and location

\begin{tabular}{llll}
\hline $\begin{array}{l}\text { Pre- } \\
\text { eclampsia }\end{array}$ & Location & & \\
\cline { 2 - 3 } Central & Lateral & Total \\
\hline Present & 8 & 40 & 48 \\
Absent & 140 & 62 & 202 \\
Total & 148 & 102 & 250 \\
\hline & & Value & CL \\
\hline Sensitivity & $83.33 \%$ & $69.78 \%$ to $92.52 \%$ \\
Specificity & $69.31 \%$ & $62.45 \%$ to $75.59 \%$ \\
Positive predictive value & $39.22 \%$ & 33.60 to $45.13 \%$ \\
Negative predictive value & $94.59 \%$ & $90.23 \%$ to $97.07 \%$ \\
\hline
\end{tabular}

had central placenta and all other 40 women had lateral placenta. The sensitivity of the test is $83.33 \%$ (CI $69.78 \%$ to $92.52 \%$ ), specificity is $69.31 \%$ (CI $-62.45 \%$ to 75. $59 \%$ ), positive predictive value is $39.22 \%$ (CI -33.6 to $45.13 \%$ ) and negative predictive value is $94.59 \%$ (CI $90.23 \%$ to $97.07 \%$ ), $\mathrm{p}$ value is $<0.0001$. Thus, the study is statistically significant (Table 5).

\section{Discussion}

Pre-eclampsia is a multi system syndrome of unknown etiology that is peculiar to human pregnancy. The placenta plays a key role in the pathogenesis of preeclampsia. The blood supply of placenta is not uniformly distributed. As such, the site of implantation and resultant location of the placenta with in uterus are likely important determinant of placental blood flow and therefore pregnancy success. There is no single screening test that can be considered reliable and costeffective for predicting pre-eclampsia.

In our study, the incidence of lateral placenta was $40.8 \%$ and of central placenta was $59.2 \%$ which is comparable to study done by Shagufta Yousuf et al (2016) $)^{5}$ in where out of 201 patients $36 \%$ had lateral placenta and $64 \%$ had central placenta. Our study is also similar to the study of Rajeshwary Pillay et $\mathrm{al}^{6}$ done at institute of Mother and Child Health, government medical college Kozhikode in period of 10 months form, December 2012 - October 2013 in a total of 100 placenta and 2 patients had central placenta (Table 4). In total 250 patients, 37 newborn shifted to NICU, in which 24 mothers were having lateral placenta and 13 mothers were having central placenta. In total 250 patients, 48 patients developed pre-eclampsia in which only 8 women women, where $32 \%$ women had lateral placenta and $68 \%$ women had central placenta.

Alexander D Kofinas et $\mathrm{al}^{7}$ study a total of 300 patients. Out of that 153 pregnancies were uncomplicated and 147 pregnancies were complicated. This study showed the unilateral placental location had a 2.8 - fold 
Table 6: Comparison of various screening tests

\begin{tabular}{lcccc}
\hline Screening Test & $\begin{array}{c}\text { Sensitivity } \\
(\%)\end{array}$ & $\begin{array}{c}\text { Specificity } \\
(\mathbf{\%})\end{array}$ & $\begin{array}{c}\text { Positive } \\
\text { Predictive } \\
\text { value (\%) }\end{array}$ & $\begin{array}{c}\text { Negative } \\
\text { Predictive } \\
\text { Value (\%) }\end{array}$ \\
\hline Mid trimester B P & 44 & 87 & 9 & 98 \\
Urinary albumin creatinine ratio & 64 & 84 & 43 & 94 \\
Hand grip test & 81 & 96 & 81 & 96 \\
Platelet angiotensin II binding & 50 & 88 & 60 & 84 \\
Abnormal RI on Doppler & 47 & 81 & 44 & 83 \\
Placental laterality (in Pai study) & 73 & 86 & 51 & 94 \\
Placental lat (in present study) & 83.33 & 69.31 & 39.22 & 94.59 \\
\hline
\end{tabular}

IUGR is a failure to achieve the growth potential of a fetus that is promised by the genetic constitution and environmental influences endogenous to the pregnancy. Fetal growth depends on the interactions of genetic and epigenetic determinants functioning against an environment of maternal, fetal and placental influences. IUGR places the fetus and neonate at risk or disability in the potential period. In women with centrally located placenta both uterine arteries demonstrate similar resistance whereas, in lateral placenta the degree of collateral circulation may not be the same in all women and deficient contribution facilitates the development of IUGR. Out study showed a significant association between laterality of placenta IUGR, which is comparable to Sumathi et $\mathrm{al}^{10}$, Neetu Singh et $\mathrm{al}^{11}$ and Rajeshwary Pillay et $\mathrm{al}^{6}$ studies. Our study is very similar to the study of Pai Muralidhar V et al $(2005)^{4}$ where placental location was determined by USG at between 18 to 24 weeks period of gestation (POG) and between 32 to 36 weeks POG. There is 5 fold higher incidence of $\mathrm{PE}$ with unilateral placenta. Among the various predictors of pre eclampsia, the placental location determined by USG is very cost effective; non invasive and statistically significant (Table 6).

\section{Conclusion}

From the above study it is concluded that unilateral implantation of placenta determined by USG at 18-24 weeks period of gestation is associated with an increased risk of pre-eclampsia, IUGR or both. Thus, ultrasonologically determined lateral location of placenta can be used as easy, non invasive, cost-effective predictor of pre eclampsia and other adverse pregnancy outcomes. So, these pregnancies may require careful obstetric management to achieve a more favourable outcome and decrease the maternal and perinatal morbidity and mortality associated with pre eclampsia. One of the major advantage of this study is it is not an extra test. From the routine anomaly scan the location of placenta can be used as a predictor. Early prediction of pre eclampsia prevents 
dreadful maternal complications thereby reduces maternal morbidity and mortality.

\section{Conflict of interest: None. Disclaimer: Nil.}

\section{References}

1.Leveno KJ, Bloom SL, Dashe JS, Casey BM, et al editors. Williams's Obstetrics. 24th edition. New York: McGrawHill; 2014. p 728-79.

2.Studd J, Lin Tan S, Chervenak FA, editors. Current Progress in Obstetrics \& Gynaecology. 4th edition. New York: Tree Life Media; 2017. p 108-54.

3.Walker JJ. Current Thought on the pathophysiology of pre eclampsia/ eclampsia. In: John Studd (ed). Progress in obstetrics \& Gynaecology. Edinburgh: Churchill Livingstone: 1988. p177-88.

4.Pai Muralidhar V, Pillai J. Placental laterality by ultrasound - a simple yet reliable predictive test for preeclampsia. Journal Obst Gynaecol India. 2005; 55(5): 431-33.

5.Yousuf S, Ahmad A, Qadir S, Gul S, et al. Utility of placental laterality and uterine artery Doppler abnormalities for prediction of pre eclampsia. The journal of obstetrics and gynaecology of India. 2016; 66 (1): 212-16.

6.Pillay R, Sanam P. Association of Lateral Implantation of Placenta with Development of Pre-Eclampsia: A Prospective Study. Journal of Evidence based Medicine and Healthcare. 2015; 2(10): 1504-8.

7.Kofinas AD, Penry M, Greiss FC, Meis PJ, et al. The Effect of placental location on uterine artery flow velocity waveforms. AM J Obstet Gynaecol. 1988; 159: 1504-8.
8.Kakkar T, Singh V, Razdan R, Digra S K, Gupta A, Kakkar M. Placental laterality as a predictor for Development of Preeclampsia. The Journal of Obstetrics and Gynecology of India. 2012; 4: 22-5.

9.Kore SJ, Khot R, Supe P, Kanavia D, Thunga C, Nandanwar Y. Prediction of pre-eclampsia: role of placental laterality by ultrasonography. International journal of Reproduction, Contraception, Obstetrics and Gynaecology. 2016; volume 5 (5), 1433-37.

10.N Sumathi, G R Pavithra. Placental laterality - A simple yet reliable Predictor of Pre Eclampsia an ultrasonic prospective study. IOSR Journal of Dental and Medical Sciences (IOSR-JDMS). 2016; 15(10):116-21.

11.Singh N, Gupta R, Pandey K, Gupta N, Chandanan A, Singh P. To study second trimester placental location as a predictor of adverse pregnancy outcome. International journal of Reproduction, Contraception, Obstetrics and Gynaecology. 2016; 5(5), 1414-17.

\section{Vandana Ambastha ${ }^{1}$, Sreelatha $\mathrm{S}^{2}$, Asha Devi ${ }^{3}$, Shruthi Kallesh ${ }^{4}$, Sumaiah ${ }^{5}$, Kavitha LB ${ }^{6}$, Sandeep ${ }^{7}$, Rajeshwari ${ }^{8}$ \\ ${ }^{1}$ Junior Resident, ${ }^{2}$ Professor, ${ }^{3}$ Assistant Professor, ${ }^{4}$ Junior Resident, ${ }^{5}$ Junior Resident, 6Junior Resident, 7Junior Resident, ${ }^{8}$ Junior Resident, Department of Obstetrics and Gynaecology, ESIC MC PGIMSR, Bangalore, Karnataka, India.}

